\title{
Chronic disease self-management competency and care satisfaction between users of public and private primary care in Singapore
}

Jun Xuan g. Ng, ${ }^{1}{ }_{M B B S}$, Joshua Chin Howe $\underline{\text { Chia }},{ }^{1}{ }_{M B B S}$, Li Yang Loo, ${ }^{1}{ }_{M B B S}$, Zhi Kai Lim, ${ }^{1}{ }_{M B B S}$, Kangshi Kho, ${ }^{1}{ }_{M B B S}$, Cynthia Chen, ${ }^{2}$ PhD, Ngan Phoon Fong, ${ }^{1,2}$ MPH

\begin{abstract}
Introduction: Primary healthcare providers play a crucial role in educating their patients on chronic disease self-management (CDSM). This study aims to evaluate CDSM competency and satisfaction in patients receiving their healthcare from public or private healthcare providers.

Methods: A cross-sectional household study was conducted in a public housing estate using a standardised questionnaire to interview Singaporeans and permanent residents aged 40 years and above, who were diagnosed with at least 1 of these chronic diseases: hyperlipidaemia, hypertension or diabetes mellitus. CDSM competency was evaluated with the Partners In Health (PIH) scale and a knowledgebased questionnaire. Satisfaction was evaluated using a satisfaction scale.

Results: In general, the 420 respondents demonstrated good CDSM competency, with 314 followed up at polyclinics and 106 by general practitioners (GPs). There was no significant difference between patients of polyclinics and GPs in CDSM competency scores (mean PIH score 72.9 vs $75.1, P=0.563$ ), hypertension knowledge scores $(90.9$ vs $85.4, P=0.16)$ and diabetes knowledge scores (84.3 vs 79.5 , $P=0.417$ ), except for hyperlipidaemia knowledge scores ( 78.6 vs $84.7, P=0.043$ ). However, respondents followed up by GPs had higher satisfaction rates than did those followed up at polyclinics (odds ratio 3.6, confidence interval 2.28-5.78). Favourable personality of the doctors and ideal consultation duration led to higher satisfaction in the GP setting. A longer waiting time led to lower satisfaction in the polyclinic group.

Conclusion: Polyclinics and GPs provide quality primary care as evidenced by high and comparable levels of CDSM competency. Redistribution of patients from public to private clinics may result in improvements in healthcare service quality.
\end{abstract}

Ann Acad Med Singap 2021;50:149-58

Keywords: Care satisfaction, chronic disease self-management, primary care, Singapore

\section{INTRODUCTION}

Primary care in Singapore is set to face challenges in managing a rapidly ageing population. The expected population of older adults aged 65 years and above will be close to 1.5 million by $2030,{ }^{1}$ corresponding to 2.7 working adults per older adult in $2030 .^{2}$ Between 2019 and 2050, Singapore is foreseen to have the second largest percentage point increase in the share of older persons in the world $(20.9 \%) .{ }^{1}$ With greater numbers of older adults, the prevalence of chronic disease and their complications is set to rise. The Transitions in Health, Employment, Social Engagement and Intergenerational Transfers in Singapore Study in 2009 found that the number of respondents with 3 or more chronic diseases have almost doubled from $19.8 \%$ to $37 \% .^{3}$ A 2017 report released by the Ministry of Health revealed that the prevalence of hyperlipidaemia, hypertension and diabetes mellitus among adults in Singapore aged 18 to 69 years were $33.6 \%, 21.5 \%$ and $8.6 \%$, respectively. ${ }^{4}$ On top of the growing burden of chronic diseases, the dependency ratio is projected to worsen to 1.1 working adults per older adult by $2080 .^{5}$ Therefore, there is a pressing need to inculcate chronic disease self-management (CDSM) to prevent disease complications and their related impact on the healthcare system at large. We understand "self-management" as patients engaging in activities that protect and promote health; monitor and manage symptoms and signs of

\footnotetext{
${ }^{1}$ Yong Loo Lin School of Medicine, National University of Singapore, Singapore

${ }^{2}$ Saw Swee Hock School of Public Health, National University of Singapore, Singapore

Correspondence: Adj Assoc Prof Ngan Phoon Fong, Saw Swee Hock School of Public Health, National University of Singapore, MD1, 12 Science Drive 2, \#10-01, Singapore 117549 .

Email: ephfnp@nus.edu.sg
} 


\section{CLINICAL IMPACT}

\section{What is New}

- Overall satisfaction scores are higher for patients followed up by GPs for chronic disease selfmanagement (CDSM).

- There is no significant difference in CDSM competency between patients followed up at polyclinics and at GP clinics.

\section{Clinical Implications}

- CDSM competency and care satisfaction can serve as quality indicators to benchmark performance of public and primary healthcare providers.

- Policies to increase accessibility to GPs for the management of chronic diseases may improve service quality in primary care.

illness; manage the impacts of illness on functioning, emotions and interpersonal relationships; and adhering to treatment regimens. ${ }^{6}$ When patients are more enabled to optimise their health, health outcomes improve consequently and the strain placed on our finite healthcare resource is relieved.

It is peculiar that CDSM is not a widely explored concept despite Singapore having a high burden of chronic diseases. Countries like Australia, Hong Kong and the Netherlands have developed validated tools such as the Partners In Health (PIH) questionnaire to assess knowledge, attitudes and practices, and guided strategic interventions to improve the health of their communities. Additionally, CDSM in itself is recognised as an important determinant for good health outcomes. ${ }^{7}$ Primary care plays a central role in entrenching CDSM. Primary care physicians form the frontline of contact with patients having early chronic diseases. Their role cannot be overstated in improving knowledge, attitudes and practices for effective CDSM.

There are many factors that contribute to successful CDSM. One factor of particular interest is access to primary care. This varies between countries and healthcare systems, but it can be generalised as access through government-funded public institutions or privately owned practices. In Singapore, these are government-funded polyclinics or general practitioner (GP) clinics, respectively. Each mode of access has its advantages and disadvantages. Polyclinics have greater capabilities to handle a large volume of integrated and government-subsidised medical care, but they are often overloaded with patients, resulting in shorter consultation duration and longer waiting times. ${ }^{8}$ GP clinics are convenient to attend, with greater accessibility, longer consultation duration and shorter waiting times, but are less affordable than polyclinics. These factors may contribute to differences in CDSM by patients who visit polyclinics and GP clinics.

We aimed to compare differences in CDSM among users of public and private primary healthcare by studying a sample population in Queenstown public housing estate in Singapore. By appraising the differences in knowledge, perspectives and practices relating to selfmanagement of 3 common chronic diseases, namely hyperlipidaemia, hypertension and diabetes mellitus, it would benefit primary healthcare systems and provide future recommendations to improve the health of our communities.

\section{METHODS}

The study used data collected from a cross-sectional, standardised, questionnaire-based survey administered by trained interviewers from 1 February to 3 February 2019. Inclusion criteria for the study were: (1) residents residing in randomly selected blocks of Housing and Development Board (HDB) flats in Queenstown housing estate; (2) Singaporean or Singapore permanent residents; (3) aged 40 years or above; (4) a medical diagnosis of at least 1 chronic disease (i.e., hyperlipidaemia, hypertension or diabetes mellitus); and (5) being mentally competent and able to give informed consent.

Responses were collected on the secure online National University of Singapore (NUS) MySurvey platform. Ethics approval was sought from the NUS Institutional Review Board (IRB no. S-18-385E) and informed consent was obtained from all participants. They were also given information on how to withdraw their consent.

Queenstown was chosen as the study site due to its older demographic profile, with $56.1 \%$ of the Queenstown community being 40 years and above. ${ }^{9}$ Thirty blocks of flats in the Queenstown estate were randomly selected and every household in each block was visited for responses. Households that did not open their doors to surveyors on the first day were revisited once the next day to reduce non-response bias.

The 12-item PIH scale developed by Flinders Behavioural Health uses a $0-8$ Likert scale in the domains of knowledge, symptom management, adherence and coping. ${ }^{6}$ The questions in the scale refers to any chronic conditions and is useful in evaluating practices in CDSM. A higher score implies better CDSM. The scale has been 
validated in Mandarin and English in a Chinese majority population in Hong Kong, ${ }^{10}$ with demographics similar to Singapore. The Cronbach alphas of the study subscales ranged from $0.773-0.845$. The PIH scale was also found to be reliable in Dutch and Australian studies. ${ }^{11,12}$

The patient-doctor relationship forms an important foundation for the empowerment of CDSM. To assess the respondents' satisfaction, defined as the fulfilment of patient expectations on medical care for their chronic disease, each respondent rated their satisfaction on a scale of 1-5 across 6 separate items. In analysis, scores of 4 and 5 implied satisfaction while 1-3 implied dissatisfaction. The total satisfaction score ranged from 6-30. Scores were placed into 4 different categories: 6-19, 20-24, 25-29, and 30 according to the frequency distribution.

To assess knowledge, respondents with hyperlipidaemia, hypertension or diabetes mellitus or any combination of these medical conditions were asked 3 factual questions. Scores were categorised into either $100 \%$ correct or not. Having $100 \%$ meant they answered all 3 questions correctly for the relevant chronic disease(s).

Data were analysed with SPSS Statistics software version 25 (IBM Corp, Armonk, US). Continuous variables were expressed as mean and standard deviation (SD) for symmetric data, and as median and interquartile range for skewed data. Categorical variables were represented as number and percentage. Prevalence of sociodemographic and confounders were tabulated, and differences in location of follow-up care (polyclinic versus GP clinic) were analysed using independent t-test (symmetric data), Mann-Whitney U test (skewed data) and chi-square test (categorical variables).

Multivariate regression analyses were performed on the satisfaction score to examine the association of confounders. A binary logistic regression was used for the satisfaction score. The regression models included only respondents who were followed up at polyclinics or GP clinics $(n=420)$. In each regression model, sets of variables were added in a forward stepwise order, adjusting for location of care, sociodemographics, lifestyle factors and disease factors. Respondents from Family Medicine Clinics and hospital specialist outpatient clinics were not included. Family Medicine Clinics, although primary physician led, are teambased and patient-centred, incorporating services from relevant allied health professionals. ${ }^{13}$

\section{RESULTS}

A total of 502 respondents were recruited for the study. The response rate from door-to-door recruitment was $62 \%$ (502 of 810 households). Of the respondents, 314
(62.5\%) were followed up at polyclinics; $106(21.1 \%)$ at GPs; $18(3.6 \%)$ at Family Medicine Clinics; $54(10.8 \%)$ at hospital specialist outpatient clinics; and $10(2.0 \%)$ were not followed up.

\section{Sociodemographic profile of respondents}

Table 1 shows the sociodemographic profile of respondents. Patients followed up at polyclinics were older when compared to those followed up by GPs (70.3 versus 66.3 years). Polyclinic patients when compared to GP patients had lower socioeconomic statuses, with lower educational qualifications (for primary school: $59.2 \%$ vs $36.8 \%$ ) and smaller housing types (HDB 3-room or smaller: $71.3 \%$ vs $63.2 \%$ ). More polyclinic patients had blue Community Health Assist Scheme (CHAS) cards $(51.0 \%$ vs $34.9 \%)$. They also had higher rates of diabetes mellitus (42.4\% vs $30.2 \%)$ and rarely chose food with "Healthier Choice" labels (48.7\% vs $34.0 \%)$.

\section{PIH, knowledge and satisfaction scores}

The mean PIH CDSM score was not statistically different between those followed up by GPs (75.1, SD 13.2) and those followed up at polyclinics (72.9, SD 13.6) (Table 2).

Mean knowledge scores for chronic diseases diabetes and hypertension were not statistically different between those followed up by GPs (90.9 and 85.4, respectively) and those followed up at polyclinics (84.3 and 79.5, respectively). Patients followed up by GPs had slightly better knowledge of hyperlipidaemia than did polyclinic patients (84.7 vs 78.6, $P=0.043$ ) (Table 2).

Our study showed higher mean satisfaction scores for those followed up by GPs than those followed up at polyclinics (26.8 vs $24.1, P<0.001)($ Table 2$)$.

\section{Multivariate regression analysis of variables on satisfaction with care}

Respondents followed up at polyclinics were 0.28 time less likely than those followed up by GPs to be satisfied with care $(95 \%$ confidence interval [CI] $0.17-0.44$, $P<0.001$ ) (Table 3). Those living in HDB 4-room flats were 0.318 time less likely than those living in HDB 5-room flats to be satisfied with care $(95 \%$ CI 0.15-0.65, $P=0.002$ ) (Table 3).

\section{Reasons for satisfaction and dissatisfaction with care}

Respondents were further divided into 2 groups to further analyse the reasons for their satisfaction and dissatisfaction in both the polyclinic and GP settings (Table 4). 
Of 314 respondents followed up at polyclinics, 228 $(73.0 \%)$ were satisfied with their care while $86(27.0 \%)$ were dissatisfied. For GP clinics, $92(87.0 \%)$ of 106 respondents were satisfied while $14(13.0 \%)$ were dissatisfied with their care.
Compared with polyclinic patients, GP patients attributed their satisfaction to the good personality of their doctors $(55.4 \%$ vs $36.0 \%, P=0.001)$ and the ideal consultation duration $(19.6 \%$ vs $11.4 \%, P=0.044)$. Other reasons associated with satisfaction included low costs,

Table 1. Sociodemographic profile of respondents followed up at general practitioner clinic and polyclinic

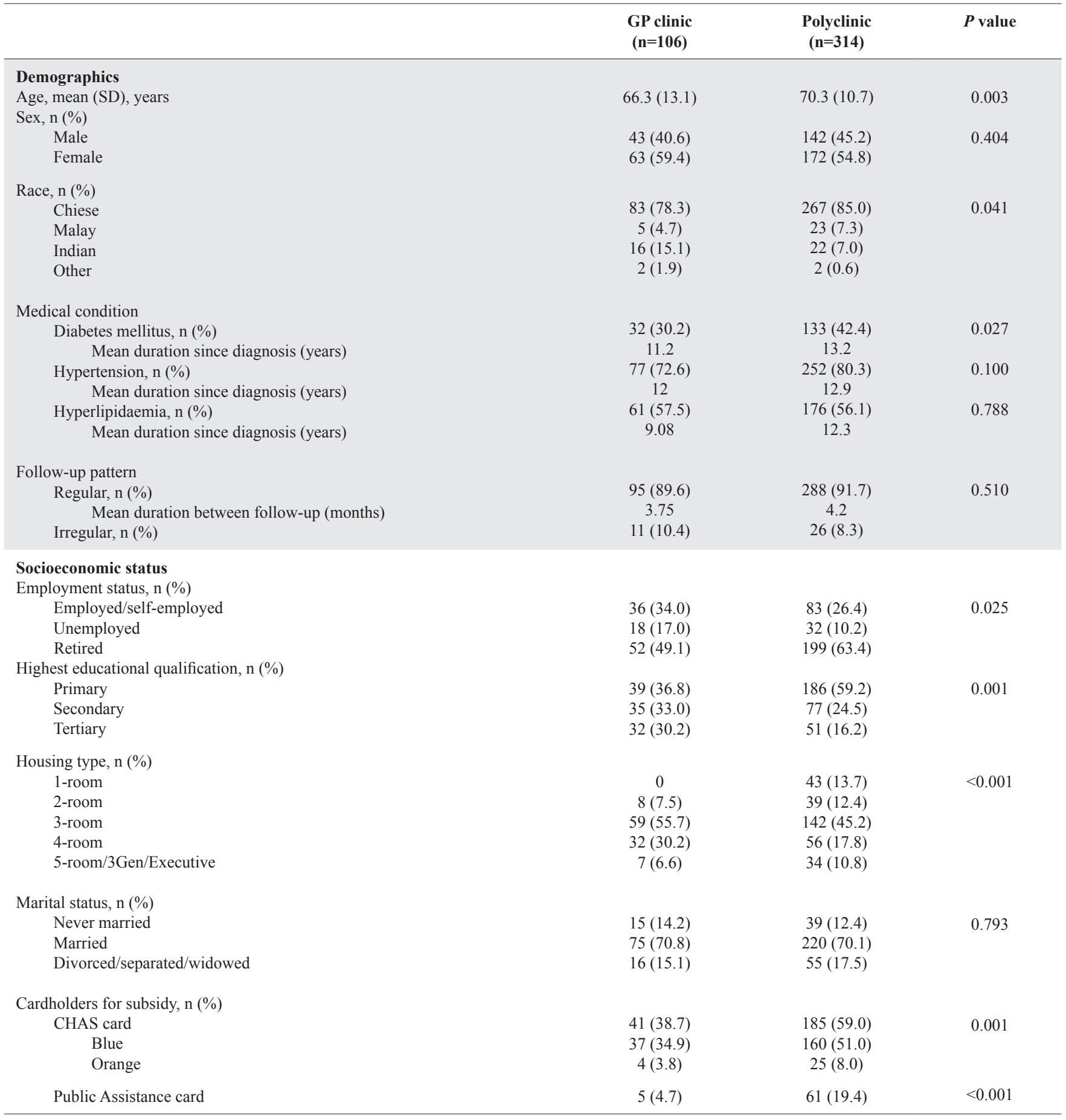

CHAS: Community Health Assist Scheme; 3Gen: 3-generation flat; GP: general practitioner 
Table 1. Sociodemographic profile of respondents followed up at general practitioner clinic and polyclinic (Cont'd)

\begin{tabular}{|c|c|c|c|}
\hline & $\begin{array}{l}\text { GP clinic } \\
(\mathrm{n}=106)\end{array}$ & $\begin{array}{l}\text { Polyclinic } \\
(n=314)\end{array}$ & $P$ value \\
\hline \multicolumn{4}{|l|}{ Lifestyle factors } \\
\hline \multicolumn{4}{|l|}{ Frequency of choosing food with the "Healthier Choice" label, n (\%) } \\
\hline Never/rarely & $36(34.0)$ & $153(48.7)$ & 0.001 \\
\hline Sometimes/most of the time & 43 (40.6) & $123(39.2)$ & \\
\hline Always & $27(25.5)$ & $38(12.1)$ & \\
\hline Seen a health professional (e.g. dietician, doctor, nurse) to manage diet, n (\%) & $46(43.4)$ & $118(37.6)$ & 0.289 \\
\hline \multicolumn{4}{|l|}{ Frequency of eating 2 portions of vegetables and fruits daily, $n(\%)$} \\
\hline Never/rarely & $9(8.5)$ & $31(9.8)$ & 0.098 \\
\hline Sometimes/most of the time & $36(33.9)$ & $140(44.6)$ & \\
\hline Always & $61(57.5)$ & $143(45.5)$ & \\
\hline \multicolumn{4}{|l|}{ Smoking, n (\%) } \\
\hline Current smoker & $7(6.6)$ & $31(9.9)$ & 0.403 \\
\hline Ex-smoker & $9(8.5)$ & $35(11.1)$ & \\
\hline Non-smoker & $90(84.9)$ & $248(79.0)$ & \\
\hline
\end{tabular}

CHAS: Community Health Assist Scheme; GP: general practitioner

Table 2. Comparison of general practitioner clinic and polyclinic in terms of Partners In Health (PIH), knowledge and satisfaction scores

\begin{tabular}{lccc}
\hline & GP clinic & Polyclinic & P value \\
\hline PIH score, mean (SD) & $75.1(13.2)$ & $72.9(13.6)$ & 0.563 \\
Knowledge score, mean (SD) & & & \\
$\quad$ Diabetes mellitus & $85.4(18.8)$ & $79.5(26.5)$ & 0.407 \\
$\quad$ Hypertension & $90.9(16.8)$ & $84.3(23.5)$ & 0.160 \\
$\quad$ Hyperlipidaemia & $84.7(23.2)$ & $78.6(27.4)$ & 0.043 \\
Satisfaction score, mean (SD) & $26.8(4.13)$ & $24.1(5.11)$ & 0.096 \\
\hline
\end{tabular}

GP: general practitioner; SD: standard deviation

Table 3. Multivariate regression analysis of variables on satisfaction rate

\begin{tabular}{lcc}
\hline & Odds ratio (95\% CI) & $P$ value \\
\hline Follow-up at polyclinic & $0.275(0.173-0.438)$ & $<0.001$ \\
\hline Follow-up at GP or workplace GP clinic & $1[$ Reference] & 0.292 \\
\hline Age, years & $1.012(0.99-1.035)$ & 0.160 \\
\hline Man & $0.735(0.478-1.13)$ & 0.178 \\
\hline Woman & $1[$ Reference $]$ & 0.090 \\
\hline Malay race & $1.702(0.785-3.695)$ & 0.976 \\
\hline Indian race & $1.870(0.907-3.857)$ & $1.029(0.159-6.666)$ \\
\hline Other races & $1[$ Reference $]$ & 0.666 \\
\hline Chinese race & $1.122(0.667-1.885)$ & 0.986 \\
\hline Employed/self-employed & $1.005(0.548-1.846)$ & $1[$ Reference] \\
\hline Unemployed & $0.933(0.344-2.535)$ & 0.893 \\
\hline Retired & &
\end{tabular}


Table 3. Multivariate regression analysis of variables on satisfaction rate (Cont'd)

\begin{tabular}{|c|c|c|}
\hline & Odds ratio $(95 \% \mathrm{CI})$ & $P$ value \\
\hline 2-room HDB flat & $1.057(0.453-2.467)$ & 0.898 \\
\hline 3-room HDB flat & $0.638(0.325-1.254)$ & 0.192 \\
\hline 4-room HDB flat & $0.318(0.154-0.654)$ & 0.002 \\
\hline 5-room HDB flat & 1 [Reference] & \\
\hline Primary education & $0.798(0.444-1.435)$ & 0.451 \\
\hline Secondary education & $0.823(0.463-1.462)$ & 0.506 \\
\hline Tertiary education & 1 [Reference] & \\
\hline Never married & $0.806(0.46-1.412)$ & 0.450 \\
\hline Divorced/separated/widowed & $0.908(0.543-1.519)$ & 0.714 \\
\hline Married & 1 [Reference] & \\
\hline Blue CHAS cardholder & $0.762(0.501-1.16)$ & 0.205 \\
\hline Orange CHAS cardholder & $1.636(0.765-3.501)$ & 0.205 \\
\hline No CHAS card & 1 [Reference] & \\
\hline Public Assistance cardholder & $1.754(0.943-3.261)$ & 0.076 \\
\hline No Public Assistance card & 1 [Reference] & \\
\hline Irregular follow-up with doctor & $0.593(0.309-1.142)$ & 0.119 \\
\hline Regular follow-up with doctor & 1 [Reference] & \\
\hline Never or rarely chooses healthier choice option & $0.780(0.441-1.381)$ & 0.394 \\
\hline Sometimes or most of the time chooses healthier choice option & $0.849(0.476-1.511)$ & 0.577 \\
\hline Always chooses healthier choice option & 1 [Reference] & \\
\hline Not seen a health professional to manage diet & $1.131(0.763-1.677)$ & 0.541 \\
\hline Seen a health professional to manage diet & 1 [Reference] & \\
\hline Never or rarely eats 2 portions of vegetables and fruits daily & $0.587(0.298-1.156)$ & 0.124 \\
\hline Sometimes or most of the time eats 2 portions of vegetables and fruits daily & $0.770(0.514-1.156)$ & 0.208 \\
\hline Always eats 2 portions of vegetables and fruits daily & 1 [Reference] & \\
\hline Weekly minutes of moderate physical activity & $1.001(1-1.001)$ & 0.111 \\
\hline Weekly minutes of vigorous physical activity & $1.000(0.997-1.002)$ & 0.762 \\
\hline Current smoker & $0.718(0.358-1.442)$ & 0.352 \\
\hline Ex-smoker & $0.801(0.416-1.54)$ & 0.505 \\
\hline Non-smoker & 1 [Reference] & \\
\hline No diabetes mellitus & $1.049(0.704-1.564)$ & 0.813 \\
\hline Diabetes mellitus & 1 [Reference] & \\
\hline No hypertension & $1.068(0.675-1.69)$ & 0.777 \\
\hline Hypertension & 1 [Reference] & \\
\hline No hyperlipidaemia & $0.817(0.554-1.204)$ & 0.308 \\
\hline Hyperlipidaemia & 1 [Reference] & \\
\hline
\end{tabular}

CHAS: Community Health Assist Scheme; CI: confidence interval; GP: general practitioner; HDB: Housing and Development Board 
Table 4. Comparison of reasons for satisfaction and dissatisfaction between general practitioner clinic and polyclinic

\begin{tabular}{|c|c|c|c|}
\hline & GP clinic & Polyclinic & $P$ value \\
\hline Satisfaction, n (\%) & $92(87.0)$ & $228(73.0)$ & \\
\hline \multicolumn{4}{|l|}{ Reasons for satisfaction, $\mathrm{n}(\%)$} \\
\hline Good personality of doctor & $51(55.4)$ & $82(36.0)$ & 0.001 \\
\hline Perceived effective care & $74(80.4)$ & $167(73.2)$ & 0.113 \\
\hline Ideal duration of consultation & $18(19.6)$ & $26(11.4)$ & 0.044 \\
\hline Low cost & $12(13.0)$ & $36(15.8)$ & 0.332 \\
\hline Short waiting time & $14(15.2)$ & $25(11.0)$ & 0.192 \\
\hline Dissatisfaction, n (\%) & $14(13.0)$ & $86(27.0)$ & \\
\hline \multicolumn{4}{|l|}{ Reasons for dissatisfaction, $\mathrm{n}(\%)$} \\
\hline Poor personality of doctor & $2(14.3)$ & $14(16.3)$ & 0.605 \\
\hline Perceived ineffective care & $3(21.4)$ & $26(30.2)$ & 0.373 \\
\hline Non-ideal duration of consultation & $4(28.6)$ & $13(15.1)$ & 0.190 \\
\hline High cost & $2(14.3)$ & $9(10.5)$ & 0.477 \\
\hline Long waiting time & $0(0.0)$ & $30(34.9)$ & 0.004 \\
\hline
\end{tabular}

GP: general practitioner

short waiting time and perception of effective care; however, these factors were not statistically significant.

There were $34.9 \%$ of respondents in the polyclinic group that associated long waiting time with dissatisfaction, compared with $0 \%$ in the GP group $(P=0.004)$. Other reasons included high costs, poor personality of the doctor, non-ideal consultation duration and perceived ineffective care; however, these factors were not statistically significant.

\section{DISCUSSION}

Our study showed no significant differences in selfmanagement competency and knowledge of chronic diseases between a sample followed up by primary healthcare providers in the polyclinics and in GP clinics. This result suggests that both public and private care settings may be equally adept at empowering patients with chronic diseases to take charge of their health.

Poor satisfaction with care hinders the development of a beneficial relationship between patient and doctor. Patients who feel a disconnect with their healthcare provider are less likely to understand or observe the advice laid out by their physician. Poor satisfaction renders the consultation ineffective as an educational tool to empower CDSM. Hence, poor care satisfaction indirectly leads to poorer health outcomes for patients. Our data showed that the overall satisfaction scores of patients followed up by a GP were $28 \%$ higher than patients followed up at a polyclinic. The reasons for greater satisfaction with GPs included the perceived good personality of the doctor as a proxy for rapport.
Patients followed up at GP clinics have a choice of their doctor, while patients followed up at polyclinics may be assigned a different doctor at each visit depending on the schedule of the polyclinic. The ability to choose one's doctor and the opportunity for consistent follow-up by the same doctor allows GPs to build a good rapport with each patient. ${ }^{14}$ Studies have shown that patients are more satisfied with care when they have an established relationship with their doctor. ${ }^{15,16}$

An ideal duration of consultation was a significant reason for greater satisfaction in GP patients. With a lower patient load, GPs have the flexibility to tailor the duration of a consultation to meet their patients' needs. Consultation time accorded by GPs for patients with chronic conditions was found to be significantly longer than the time spent by a polyclinic doctor. ${ }^{8}$ Incidentally, an ideal duration allocated for consultation may allow a physician to establish a better rapport and understanding of each patient's unique background for delivering personalised care.

A long waiting time before consultation is the main reason for dissatisfaction in polyclinic patients. On average, a physician working in the polyclinic has a higher patient load than a GP. ${ }^{8}$ We postulated that this may be the reason for the longer waiting times in the polyclinic. Nonetheless, the introduction of online appointment systems has reduced the waiting time for patients in polyclinics in recent years. ${ }^{17}$

An ageing population brings about a greater proportion of the population with chronic diseases. It brings into question how healthcare resources can be best optimised 
to meet the needs of the population. In accordance with the Singapore Healthcare 2020 Masterplan goals of achieving better quality care for patients, the Singapore government has focused on expanding polyclinic capacity to deal with the increasing health burden of the community in recent years. However, based on statistics from the latest Primary Care Survey conducted in 2014, polyclinic doctors have still been attending to more patients a day compared with their GP counterparts in primary care. ${ }^{8}$ Improvement in patient satisfaction in the polyclinic setting, in view of the limited consultation time, may require systemic strategies such as follow-up by a regular doctor based on the teamlet care model, or expanding on outpatient doctor-patient interaction with, for instance, teleconsultations. Yet, we acknowledge that such strategies have its inherent limitations.

We postulate that a win-win scenario may be achieved by encouraging more patients to be followed up by GPs for their chronic conditions. By encouraging patients to make the switch to GPs, the patient load on the public primary healthcare setting served primarily by the polyclinics can be decreased, thereby reducing waiting times to improve satisfaction levels among the remaining patients followed up at the polyclinic. Patients who make the switch from polyclinics to GPs will benefit from a greater rapport with the same primary care physician at each consultation.

Although the majority of primary healthcare is managed in the GP setting in Singapore, ${ }^{8}$ a large proportion of chronic disease primary care is currently managed by the polyclinics. This may be driven largely by significant subsidies given to patients who patronise the public healthcare sector.

In recent years, several schemes have been introduced to support chronic disease follow-up in the private GP sector. These programmes include direct subsidies given to patients in the form of the CHAS scheme, as well as non-financial support for GPs to improve infrastructure and accessibility of services required for chronic disease care, in the form of Primary Care Networks (PCN), ${ }^{18}$ access to electronic medical records, and collaborations with healthcare clusters. Since our study was concluded, an enhanced CHAS scheme was also introduced in November 2019 with subsidies for chronic disease follow-up by GPs being extended to all Singaporeans. During a parliamentary debate in March 2020, it was announced that Singapore will have at least half of CHAS GP clinics participating in PCN by the end of 2020, with more than 500 PCN GP clinic partners caring for more than 100,000 patients with chronic diseases. ${ }^{19}$ The effects of these government policies will be of interest in the coming years.

Apart from the effective organisation of healthcare services, the concept of self-management support as introduced by Wagner in the Chronic Care Model ${ }^{20}$ highlights the importance of educational interventions, skills empowerment, and psychosocial support that is crucial to improving CDSM. Primary care providers should pay more attention to inculcating in their patients a sense of ownership over their own health. Many patients are familiar with the various patient education activities conducted by primary care facilities nationwide to inform and correct misconceptions on chronic diseases, thereby influencing practices. Empowerment can also come in the form of encouraging health-conscious practices such as regular blood pressure and glucose self-monitoring. By cultivating self-management knowledge, attitudes and practices, patients and physicians can then work synergistically to optimise care. To this end, self-management can be greatly improved with structured self-management support programmes that have come into existence, such as the Flinders Chronic Condition Management Program, ${ }^{21}$ which combines assessment tools to identify lapses in CDSM and therefore develop an individualised intervention plan to improve CDSM and hence health outcomes.

\section{Strengths and limitations of the study}

While we used metabolic syndromes as the subject for analysis of CSDM competency, we understand that the breadth of chronic diseases stretches beyond, including diseases like depressive disorders, the incidence of which has been rising steadily over the years. Admittedly, we did not include primary care providers participating in teamlet models of care in polyclinics or Family Medicine Clinics in the analysis of associations, although these models of care are slowly gaining popularity. Certain limitations exist with the use of our scoring systems. While an association may be drawn with increasing knowledge scores and better health literacy, the 3-point tool may not be adequately sensitive or discerning. Being a cross-sectional study, our results demonstrate correlation between variables and not causality. Pinpointing the exact reason behind better PIH or knowledge scores would require further assessments via cohort studies to track trends and associations over longer periods. Previous research has found that chronic diseases led to negative quality of life in patients suffering 
from diabetes ${ }^{22}$ and respiratory disorders ${ }^{23}$ in Asia. It may be worth exploring further the relationship between CDSM competency and quality of life in individuals with chronic illnesses.

\section{CONCLUSION}

Our study is the first of its kind in Singapore to evaluate CDSM in primary care. Assessment of CDSM is a crucial aspect to consider in the quality evaluation of chronic disease management, which can be used subsequently to benchmark quality of care. Our findings, based on respondents from a public housing estate with an older demographic profile, provide insights that may inform the allocation of primary care resources for improving existing models of community care.

While we found no significant difference in the knowledge and practices of CDSM from respondents who were followed up at polyclinics or GP clinics, respondents who were followed up by GPs were more satisfied with their care than respondents who were followed up at polyclinics. As the perception of care appears in favour of a GP setting, redistribution of patients from public to private clinics may result in improvements in healthcare service quality.

The Singapore Healthcare 2020 Masterplan describes the goals of improving accessibility, affordability and quality of healthcare. Instead of viewing these goals separately, perhaps it is through improving accessibility that we may ultimately improve the quality of care. If so, it would be pertinent for us to tap the strengths of each primary care provider to achieve these goals.

\footnotetext{
Acknowledgements

The authors would like to thank the dedicated team members of the Community Health Projects Group 6 of medical students from Yong Loo Lin School of Medicine Class of 2020 for their invaluable contributions to the project (in no particular order): Angela CSY Heng, Low JE Aria, Jia Ling Ong, Jun Yang Tan, Farah LY Tan, Teng Wei Heng, Alpha CJ Lee, Mirza SBR Muhammad, Xinyi Qu, Evan YY Tan, Esabella ST Koh, Louisa Cheong, Yuping Ma, Xian Wang Seow, Amanda SH Tan, Chloe ZY Chen, Louis YC Chua, Basir FR Koh, Judith Ow, Bryan MH Keng, Gabriel ZH Leow, Bryan KP Hon, Zhi Xuan Ng, Tian Ci Quek, Pearl L Wee, Abhishek S Mhaisalkar, Ga Jing Kee, Benedict JD Lee, Kishore P, Raphael Q Soh and Linyi Zhang.
}

\section{REFERENCES}

1. United Nations Department of Economic and Social Affairs. World Population Ageing 2019: Highlights. Available at: https://www.un.org/en/development/desa/population/publications/
pdf/ageing/WorldPopulationAgeing2019-Highlights.pdf. Accessed on 17 May 2020.

2. Ministry of Health, Singapore. $\mathrm{MOH}$ leads review to strengthen caregiver support for seniors, 23 October 2018. Available at: https://www.moh.gov.sg/news-highlights/details/moh-leads-reviewto-strengthen-caregiver-support-for-seniors. Accessed on 9 March 2021.

3. Chan A, Malhotra R, Manap NB, et al. Transitions in Health, Employment, Social Engagement and Intergenerational Transfers In Singapore Study (THE SIGNS Study) - I: Descriptive statistics and analysis of key aspects of successful ageing, 2018. Available at: https://www.duke-nus.edu.sg/docs/librariesprovider3/research-policybrief-docs/the-signs-study---i-report.pdf. Accessed on 17 May 2020.

4. Ministry of Health, Singapore. Disease burden, 2018. Available at: https://www.moh.gov.sg/resources-statistics/singapore-health-facts/ disease-burden. Accessed on 17 May 2020.

5. Gee C, Arivalagan Y, Chao F. Harnessing Singapore's longevity dividends: The generational economy, society and policy, 2018. Available at: https://kyspp.nus.edu.sg/docs/default-source/ips/sp2018background-paper_180118.pdf. Accessed on 17 May 2020.

6. Battersby M, Ask A, Reece MM, et al. The Partners in Health scale: The development and psychometric properties of a generic assessment scale for chronic condition self-management. Aust J Prim Health 2003;9:41-52.

7. Coleman MT, Newton KS. Supporting self-management in patients with chronic illness. Am Fam Physician 2005;72:1503-10.

8. Ministry of Health, Singapore. Primary Care Survey 2014. Available at: https://www.moh.gov.sg/docs/librariesprovider5/resourcesstatistics/reports/moh-primary-care-survey-2014-report.pdf. Accessed on 17 May 2020.

9. Department of Statistics, Singapore. Geographic Distribution Latest Data, 2018. Available at: https://www.singstat.gov.sg/finddata/search-by-theme/population/geographic-distribution/latest-data. Accessed on 17 May 2020.

10. Chiu TM, Tam KT, Siu CF, et al. Validation study of a Chinese version of Partners in Health in Hong Kong (C-PIH HK). Qual Life Res 2017;26:199-203.

11. Heijmans M, Waverijn G, Rademakers J, et al. Functional, communicative and critical health literacy of chronic disease patients and their importance for self-management. Patient Educ Couns 2015;98:41-8.

12. Petkov J, Harvey P, Battersby M. The internal consistency and construct validity of the Partners in Health scale: Validation of a patient-rated chronic condition self-management measure. Qual Life Res 2010;19:1079-85.

13. National University Health System, Singapore. Care in the community, 9 April 2020. Available at: https://www.nuhs.edu.sg/Carein-the-Community/Living-Well/Pages/Family-Medicine-Clinics.aspx. Accessed on 2 March 2021.

14. Rubin G, Bate A, George A, et al. Preferences for access to the GP: A discrete choice experiment. Br J Gen Pract 2006;56:743-8.

15. Saultz JW, Albedaiwi W. Interpersonal continuity of care and patient satisfaction: A critical review. Ann Fam Med 2004;2:445-51.

16. Schers $\mathrm{H}$, van den Hoogen $\mathrm{H}$, Bor $\mathrm{H}$, et al. Familiarity with a GP and patients' evaluations of care. A cross-sectional study. Fam Pract 2005;22:15-9.

17. Ministry of Health, Singapore. Effectiveness of online appointment system in reducing waiting time at polyclinics, 1 April 2019. 
Available at: https://www.moh.gov.sg/news-highlights/details/ effectiveness-of-online-appointment-system-in-reducing-waiting-timeat-polyclinics. Accessed on 17 May 2020.

18. Ministry of Health, Singapore. Primary Care Networks, 2019. Available at: https://www.moh.gov.sg/home/our-healthcare-system/ healthcare-services-and-facilities/primary-care-networks. Accessed on 17 May 2020.

19. Ministry of Health, Singapore. Speech by Dr Lam Pin Min, Senior Minister of State, Ministry of Transport and Ministry of Health, at the Ministry of Health Committee of Supply Debate 2020, 5 March 2020. Available at: https://www.moh.gov.sg/news-highlights/ details/speech-by-dr-lam-pin-min-senior-minister-of-state-ministry-oftransport-and-ministry-of-health-at-the-ministry-of-health-committeeof-supply-debate-2020-on-thursday-5-march-2020. Accessed on 30 May 2020.
20. Wagner EH. Care of older people with chronic illness. In: Calkins E, Boult C, Wagner EH, et al. New Ways to Care for Older People: Building Systems Based on Evidence. New York: Springer; 1999:39-64.

21. Battersby M, Harris $M$, Smith $D$, et al. A pragmatic randomized controlled trial of the Flinders Program of chronic condition management in community health care services. Patient Educ Couns 2015;98:1367-75.

22. Nguyen HV, Tran TT, Nguyen CT, et al. Impact of comorbid chronic conditions to quality of life among elderly patients with diabetes mellitus in Vietnam. Int $\mathrm{J}$ Environ Res Public Health 2019;16:531.

23. Ngo CQ, Phan PT, Vu GV, et al. Effects of different comorbidities on health-related quality of life among respiratory patients in Vietnam. J Clin Med 2019;8:214. 